\title{
Necrotizing Fasciitis of the Breast: A Case Managed without Mastectomy
}

\author{
M.O. Soliman ${ }^{a} \quad$ E.H. Ayyash ${ }^{\text {a }} \quad$ A. Aldahham ${ }^{a} \quad$ S. Asfar ${ }^{a, b}$ \\ Department of Surgery, ${ }^{a}$ Mubarak Al-Kabeer Hospital, and ${ }^{b}$ Faculty of Medicine, Kuwait University, Jabriya, Kuwait
}

\section{Key Words}

Breast abscess $\cdot$ Necrotizing fasciitis

\begin{abstract}
Objective: To report a rare presentation of necrotizing fasciitis (NF) in the breast and its management. Clinical Presentation and Intervention: A 61-year-old non-diabetic lady presented with a painful swollen right breast and yellowish discharge associated with fever for the last few days. Based on clinical examination and haematological parameters, a provisional diagnosis of breast abscess was made that later proved to be a case of NF. She was managed conservatively with repeated debridement followed by split-skin grafting with preservation of the breast. Conclusion: This case showed that NF of the breast can present as a simple breast abscess which was managed conservatively.
\end{abstract}

Copyright ๑ 2011 S. Karger AG, Basel

\section{Introduction}

Necrotizing fasciitis (NF) is a progressive severe infective gangrene of the subcutaneous tissue with subsequent death of the overlying skin. It is a life-threatening condi- tion associated with a high mortality rate. NF of the breast is rare, only 4 cases have been reported in the literature [1]. It may masquerade as a simple breast abscess which leads to delay in implementing the appropriate management. It should be suspected whenever a breast abscess presents in a non-lactating woman. It may present as primary infection of the breast or secondary to a minor intervention like core needle biopsy. Most reported cases ended in mastectomy [1]. In this report we show that conservative management and avoidance of mastectomy are possible in breast NF.

\section{Case Report}

A 61-year-old not known to be diabetic lady presented with a painful swollen right breast and yellowish discharge associated with fever for the last few days. There was no history of trauma to the breast, nipple discharge, weight loss or bone pains. She reported no previous surgical procedure on the breast, and there was no family history of breast diseases.

On clinical examination she had fever, temperature $37.9^{\circ} \mathrm{C}$, blood pressure $145 / 75 \mathrm{~mm} \mathrm{Hg}$ and pulse $90 / \mathrm{min}$. The upper lateral quadrant of the right breast was erythematous, swollen, with purulent discharge from skin sinuses. The surrounding area was indurated and tender. The left breast was normal, and there was no axillary lymphadenopathy bilaterally. On admission to hospi-

\section{KARGER}

Fax +4161306 1234

E-Mail karger@karger.ch

www.karger.com
(C) 2011 S. Karger AG, Basel

1011-7571/11/0206-0567\$38.00/0

Accessible online at:

www.karger.com/mpp
Prof. Sami Asfar

Department of Surgery

Faculty of Medicine, Kuwait University

PO Box 24923, Safat 13110 (Kuwait)

Tel. +965 2531 9475, E-Mail sami@ hsc.edu.kw 
Fig. 1. Photographs of the breast showing different stages in the conservative management. a The breast at the second debridement shows the extensive skin loss with residual islands of necrosis. b Two weeks after the third debridement showing the extensive skin loss with sparing of the areola-nipple complex and growth of granulation tissue. c Five weeks after the third debridement just before skin grafting showing a nice carpet of healthy granulation tissue. $\mathbf{d}$ The breast after split-skin grafting ( 5 weeks after the third debridement).
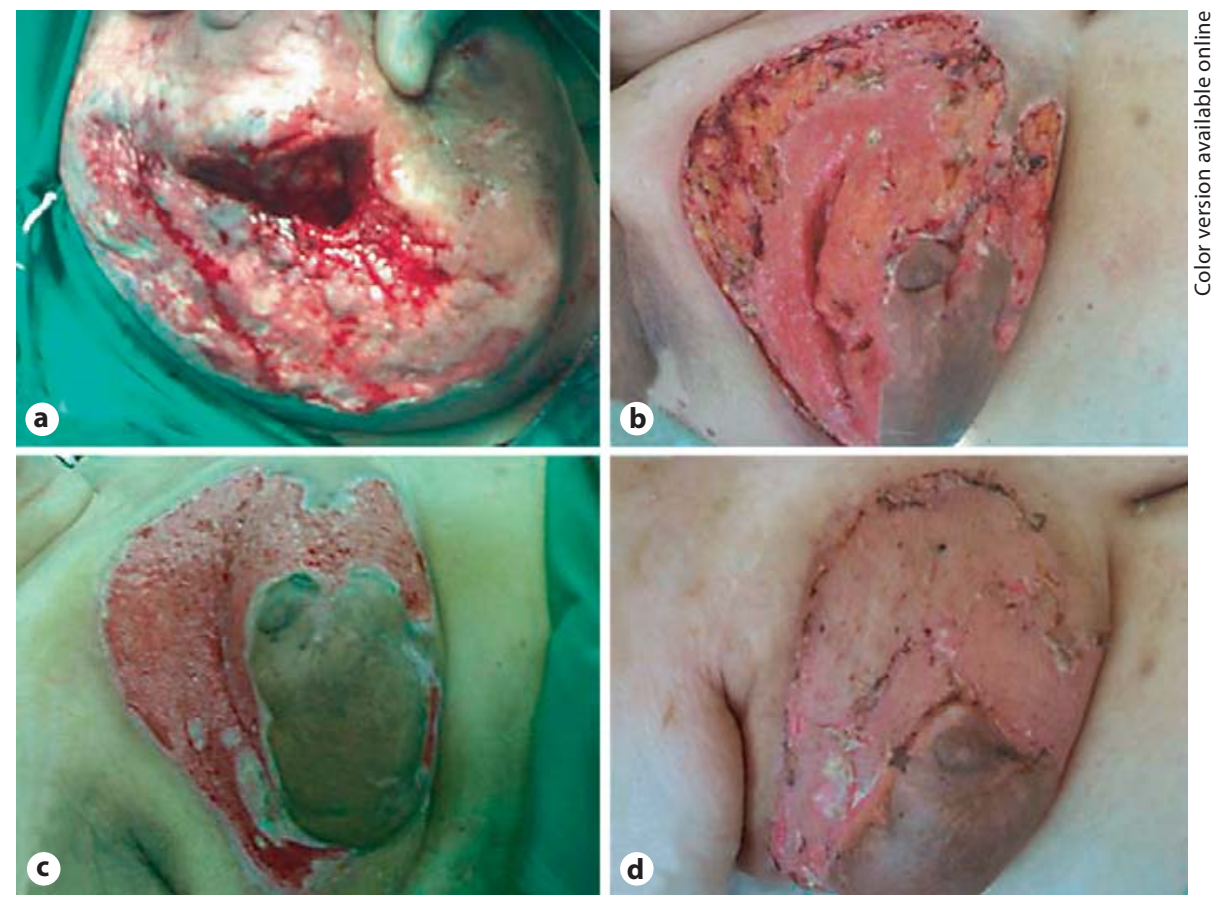

tal her white cell count was $12.9 \times 10^{9} / 1$ (normal: 3.9-10 $\left.\times 10^{9} / 1\right)$, haemoglobin $11.4 \mathrm{~g} / \mathrm{dl}$ (normal: $120-150 \mathrm{~g} / \mathrm{dl}$ ) and platelet count $320 \times 10^{9} / 1$ (normal: $\left.130-430 \times 10^{9} / 1\right)$ with normal serum creatinine and electrolytes. A provisional diagnosis of breast abscess was made, and she was accordingly started on intravenous antibiotic (Dalacin C, lincomycin $600 \mathrm{mg}$ t.d.s.) and taken to the operating room where the abscess cavity was cleaned and the cavity packed for postoperative dressing. Five pieces of abscess wall were sent for histopathological examination. The patient continued to have pain, her temperature rose to $39^{\circ} \mathrm{C}$ and the white cell count increased to $15.2 \times 10^{9} / 1$ on the fourth postoperative day. There were multiple discharging sinuses around the wound with cellulitis involving the whole breast and extending to the chest wall. A second debridement was done under general anaesthesia where all necrotic tissue was excised down to the breast tissue which looked normal (fig. 1a). She was fine for 2 days then started to have fever and severe pain in the wound, and there were new areas of necrosis in the wound depth and edges with purulent discharge. A third debridement ( 2 weeks after the first) was done with an aggressive excision of all necrotic tissue leading to a large area of skin and subcutaneous tissue loss sparing the nipple and areola complex. Based on the tissue culture, the intravenous antibiotic was changed to intravenous Tazocin every $8 \mathrm{~h}$ (piperacillin $2 \mathrm{~g}+$ $0.5 \mathrm{~g}$ tazobactam). Following that, the patient continued to improve, and the wound started to granulate nicely (fig. 1b). Five weeks after the last debridement, a split-skin graft was done with excellent results (fig. 1c, d).

Histopathology of the tissue removed during debridement showed acute necrotizing inflammation with abscess formation and fat necrosis consistent with the diagnosis of NF. Cultures from the tissue showed Pseudomonas aeruginosa, Proteus mirabilis and Klebsiella pneumoniae.

\section{Discussion}

$\mathrm{NF}$ is an uncommon, potentially fatal condition. It consists of infection and necrosis of subcutaneous tissue and fascia with sparing of the muscles. Based on the causative organisms NF is divided into 2 types: type 1, polymicrobial infections including anaerobes, and type 2, which is caused by group A streptococcal organisms with or without staphylococci. The case presented here is type 1. It can affect any part of the body especially the trunk, lower and upper limbs, the perineum and external genitalia (Fournier's gangrene). No age group is immune; adults as well as children and neonates were reported in the literature to be affected by NF [2]. In this case, the lady was 61 years of age. More susceptible groups are immunocompromised patients, diabetics, drug abusers, patients suffering from peripheral vascular disease, and those with malignancy or chronic renal failure [1]. It may occur spontaneously or after very minor trauma like acupuncture or simple interventions like suprapubic catheter or thoracostomy tube insertion [3-5]. The clinical features may initially mimic simple cellulitis and hence the delayed diagnosis in many cases. The condition should be suspected when an area of skin redness, tenderness and swelling is associated with severe pain disproportionate to the obvious physical signs, especially in the category of patients mentioned above. Other more definite skin 
manifestations are red or dusky skin discolouration and formation of haemorrhagic skin bullae containing dirtylooking 'dishwater' fluid in addition to fever and leucocytosis [1].

NF of the breast is rarely reported; 4 cases have been reported as primary NF of the breast, i.e. with no previous trauma or intervention, mostly in non-lactating women [6-9] as in our patient. The case reported here is the fifth in the English literature. Four cases were reported secondary to intervention: 1 after core needle biopsy from the breast [10], 1 after elective mastectomy [11] and 2 cases in the German literature, the first after reduction mammoplasty and the second after mastectomy for breast cancer; both these patients died subsequent to severe NF [12]. Of the 4 reported primary NF cases, 3 required mastectomy [6-8] and only 1 case was managed conservatively without reverting to mastectomy [9]. Our case is the second in the literature successfully treated conservatively with repeated debridement and split-skin grafting.

The most important issue in the management of NF in general and the breast is immediate surgery with extensive debridement of all non-viable tissue, proper intravenous antibiotic therapy guided by culture/sensitivity results and a repeated unlimited number of debridements until no more necrotic tissue is seen as was done for our patient. For early diagnosis, clinical suspicion may not be enough especially in the breast area because of its robust nature; the skin manifestation described above may not be seen or appreciated early in the course of the disease. The use of imaging, i.e. MRI or CT scan, may help in this context. Wong and Tan [9] used MRI and were able to detect NF early and saved the patient's breast. In addition, the use of the Laboratory Risk Indicator for Necrotizing Fasciitis score may help in suspicious cases, as a score of $\geq 6$ should indicate early imaging or surgical exploration to rule out NF [9-12]. In addition, in equivocal cases one can use the 'finger test' at the bedside whereby a $2-\mathrm{cm}$ incision is made under local anaesthesia in the suspicious area followed by gentle probing with the finger down in the depth of the wound to the deep fascia. The lack of tissue resistance and the release of dirty-looking fluid characteristically called 'dishwater pus' confirms the diagnosis of NF [1] and dictates that the patient should immediately go to the operating room for proper debridement as an organ- and life-saving procedure.

\section{Conclusion}

This case showed that NF of the breast can present as a simple breast abscess which was managed conservatively.

\section{References}

1 Shimizu T, Tokuda Y: Necrotizing fasciitis. Intern Med 2010;49:1051-1057.

-2 Peker E, Kirimi E, Tuncer O, Ceylan A, Cagan E, Dogan M: Necrotizing fasciitis caused by Staphylococcus epidermidis in a neonate with extremely low birth weight. J Dermatol 2010;37:671-673.

-3 Macuha F Jr, Ahn A, Graham R: Necrotizing fasciitis associated with acupuncture: a case report. J Hosp Med 2010;5:565-568.

4 Bearman DM, Livengood CH 3rd, Addison WA: Necrotizing fasciitis arising from a suprapubic catheter site: a case report. J Reprod Med 1988;33:411-413.
5 Pingleton SK, Jeter J: Necrotizing fasciitis as a complication of tube thoracostomy. Chest 1983;83:925-926.

-6 Shah J, Sharma AK, O’Donoghue JM, Mearns B, Johri A, Thomas V: Necrotizing fasciitis of the breast. Br J Plast Surg 2001;54: 67-79.

7 Rajakannu M, Kate V, Ananthakrishnan N: Necrotizing infection of the breast mimicking carcinoma. Breast J 2006;12:266-267.

8 Nizami S, Mohiuddin K, Azam M, Zafar H, Memon MA: Necrotizing fasciitis of the breast. Breast J 2006;12:168-169. $\checkmark 9$ Wong $\mathrm{CH}$, Tan BK: Necrotizing fasciitis of the breast. Plast Reconstr Surg 2008;122: 151e-152e.

10 Flandrin A, Rouleau C, Azar CC, Dubon O, Giacalone PL: First report of a necrotising fasciitis of the breast following a core needle biopsy. Breast J 2009;15:199-201.

11 Velchuru VR, van der Walt M, Sturzaker HG: Necrotizing fasciitis in a postmastectomy wound. Breast J 2006;12:72-74.

12 Eugster T, Aeberhard P, Reist K, Sakmann K: Necrotizing fasciitis caused by beta-hemolytic streptococci with fatal outcome - a case report. Swiss Surg 1997;3:117-120. 